\title{
Literatura e química: possíveis interações
}

\section{Literature and chemistry: possible interactions}

\author{
Pablo Wolf Oliveira \\ Programa de Pós-Graduação em Ensino de Química (PEQUI), Universidade Federal do \\ Rio de Janeiro (UFRJ). \\ pablo.wolf1984@gmail.com \\ orcid.org/0000-0001-8069-955X
}

Nadja Paraense dos Santos

Instituto de Química, Universidade Federal do Rio de Janeiro (UFRJ)

nadja@iq.ufrj.br

orcid.org/0000-0003-2844-0377

Resumo.O presente trabalho mostra a importância de pensarmos no ensino de Química de forma a buscar romper barreiras disciplinares e entender o ser humano e o mundo em que ele vive através da integração de saberes de diferentes áreas de conhecimentoproporcionada pelo uso de textos literários. Pensando em um ensino de Química nessa perspectiva, selecionou-se três textos literários e pontuou-se brevemente alguns conhecimentos e reflexões que podem ser levantados a partir deles. Dessa forma, mostrou-se possibilidades de envolver os estudantes em histórias que contenham a riqueza da linguagem literária e conexões com a química.

Palavras-chave: Literatura. Química. Ensino de química.

Abstract.The present work shows the importance of thinking about teaching Chemistry in order to seek to break disciplinary barriers and understand the human being and the world in which he lives through the integration of knowledge from different areas provided by the use of literary texts. Thinking about teaching chemistry in this perspective, three literary texts were selected and some knowledge and reflections that could be raised from them were briefly scored. In this way, possibilities were shown to involve students in stories that contain the richness of literary language and connections with chemistry.

Keywords: Literature. Chemistry. Teaching chemistry. 


\section{Introdução}

É fundamental a discussão sobre o significado que o ensino de ciências, e especificamente o ensino de Química, tem para o estudante. Muito se tem falado sobre um ensino limitado à apresentação e aplicação de conceitos, fórmulas e regras de nomenclatura, e que felizmente tem evoluído para o uso de exemplos do cotidiano, a contextualização e a interdisciplinaridade. Entretanto, também é importanteentender se o ensino apresentado ajuda o estudante a compreender o ser humano e o mundo em que ele vive. Essacompreensão não pode ser conseguida se o conhecimento for trabalhado apenas de forma compartimentada, como se não fosse preciso diferentes saberes para lidar com a realidade, cujo entendimento depende de múltiplos fatores interligados.

Morin (2005) propõe a reforma do pensamento ao apresentar o problema da fragmentação dos saberes, ou seja, do isolamento desses em disciplinas, e coloca a necessidade de trabalhar esses saberes de forma integrada, o que condiz com o entendimento da realidade complexa. Essa reforma do pensamento pode ser trabalhada no ensino escolar quando, por exemplo, em uma determinada disciplina escolar existe a abertura para o diálogo com outras disciplinas e áreas de conhecimento. $\mathrm{O}$ autor afirma que os desenvolvimentos disciplinares das ciências possibilitaram uma eficiência produtiva com a divisão do trabalho, entretanto, é preciso que o aprendiz contextualize e integre conhecimentos.

O pensamento que recorta, isola, permite que especialistas e experts
tenham ótimo desempenho em seus compartimentos, e cooperem
eficazmente nos setores não complexos de conhecimento,
notadamente os que concernem ao funcionamento das máquinas
artificiais; mas a lógica a que eles obedecem estende à sociedade e às
relações humanas os constrangimentos e os mecanismos inumanos da
máquina artificial e sua visão determinista, mecanicista, quantitativa,
formalista, e ignora, oculta ou dilui tudo que é subjetivo, afetivo, livre,
criador.(MORIN, 2005, p.15)

Castro (2015) aponta a época da globalização em que estamos vivendo caracterizando-a pelo domínio dos conhecimentos técnicos na sociedade e na vida das pessoas e expõe o paradoxo de como equilibrar o desenvolvimento técnico com a valorização do humano. Além disso, alerta sobre o lugar do ser humano nessa sociedade dominada pela técnica. Partindo dessa visão, podemos dizer que o ensino de ciências precisa ser humanizado, ou seja, fazer sentido para o estudante enquanto pessoa em busca de sentido para a própria existência e inserida na sociedade.

Nessa perspectiva, é possível fazer uma crítica à separação entre o que Morin (2005) chamou de cultura humanística, que segundo este autor é aquela que estimula a reflexão 
sobre as grandes interrogações humanas, e a cultura científica, que está relacionada à busca da verdade objetiva, exterior (MORA, 2003). Para esta autora, o fluxo de conhecimento e de compreensão deve circular entre as duas culturas.

Gurgel e Watanabe (2017) defendem o ensino da ciência como cultura, entendendo a primeira como parte da cultura de uma sociedade, e então fazem um trabalho envolvendo narrativas no ensino de Física, com o objetivo de mostrar para os alunos a ciência como parte de sua cultura. Um trabalho dessa natureza caminha no sentido de preencher a lacuna deixada por um ensino baseado na resolução mecânica de problemas e traz as ciências da natureza para perto da área de linguagens e humanidades.

Na perspectiva da procura por um ensino humanista, de integração da ciência à cultura, da concepção da importância da integração de saberes e que leve o estudante a questionamentos e reflexões sobre a vida e o mundo, apresenta-se aqui a proposta de uso de textos literários no ensino de Química.

Silveira (2013) apresenta razões que corroboram para a defesa do potencial pedagógico de textos literários em aulas de Química, explicitando por exemplo: a possibilidade de humanizar a ciência; inserir o conhecimento científico em uma realidade complexa que vai além do conhecimento da disciplina de estudo; estimular a leitura e permitir a vivência de situações que vão além do conhecimento científico.

Sendo assim, o objetivo do presente trabalho é fazer uma breve explanação sobre o potencial pedagógico do uso de alguns textos literários no ensino de Química, pontuando conhecimentos e reflexões que podem ser levantados a partir da leitura de cada texto e conteúdos químicos que podem ser relacionados.

\section{Desenvolvimento}

A partir de pesquisa bibliográfica, procurou-se textos literários com potencial pedagógico para uso no ensino de Química. Buscou-se textos que permitam ao aluno e ao professor tratarem de questões relevantes do ponto de vista humano, social, histórico, científico e que possam servir como ponto de partida para trabalhar conteúdos de Química. Para este trabalho, foram selecionados três textos literários que serão apresentados aqui junto com algumas potencialidades de discussões em sala de aula.

\subsection{Um trecho do livro "Uma aprendizagem ou o Livro dos Prazeres".}

O romance "Uma aprendizagem ou o Livro dos Prazeres"(1969)é de autoria da escritora Clarice Lispector (1920-1977). De acordo com Soares (2007), romance é uma forma narrativa voltada para o homem como indivíduo tanto no aspecto histórico quanto no psicológico. A narrativa em terceira pessoa gira em torno da busca por si mesma da personagem Lóri, uma professora primária que se apaixona por Ulisses, professor de filosofia sábio e equilibrado, que espera o tempo necessário para que Lóri se sinta segura de se entregar a ele. 
O trecho selecionado para este trabalho é uma passagem que descreve a intensa alegria de Lóri em sua passagem pelo mar. A seguir temos um pequeno trecho desta passagem:

O caminho lento aumenta sua coragem secreta - e de repente ela se deixa cobrir pela primeira onda! O sal, o iodo, tudo líquido deixam-na por uns instantes cega, toda escorrendo- espantada de pé, fertilizada.

(...)Com a concha das mãos cheias de água, bebe-a em goles grandes, bons para a saúde de um corpo. (LISPECTOR, 1998, p.79)

Percebe-se neste texto o potencial de se levantar questões como a composição da água do mar, a origem dos sais no mar, a possibilidade de benefícios do banho de mar para a saúde e o valor cultural da relação do ser humano com o mar.A partir do texto, os conteúdos químicos sobre íons, compostos iônicos, soluções, soluções eletrolíticas e o estado físico do iodo podem ser trabalhados.

A continuidade da narrativa nos diz que Lóri continua mergulhando e bebendo mais água, mas "agora sem sofreguidão pois já conhece e já tem um ritmo de vida no mar. Ela é a amante que não teme pois que sabe que terá tudo de novo"(LISPECTOR, 1998, p.80). Essa passagem mostra o sucesso da personagem nesta experiência de vida, pois ela parece ter superado o medo inicial do mar e começa a ter coragem de encarar as próprias angústias íntimas.

Quando se fala em ensino dentro da proposta deste artigo, as reflexões traçadas até aqui nos levam a pensar em uma prática que conduza ao educar pelas palavras poéticas e à união entre a cultura científica e a cultura humanística. Ora, onde pode entrar a cultura científica na narrativa sobre o mar de Lóri?

Podemos começar simplesmente pensando em alguns termos utilizados na narrativa e no próprio mar, esse ambiente riquíssimo em íons dissolvidos em água.A narrativa diz: o sal, o iodo, tudo líquido... Entretanto, o iodo não é líquido. A substância simples iodo, nas condições ambiente pode estar sólida ou no estado gasoso, tem a coloração violeta e ocorre facilmente a sublimação, que é a passagem de uma substância do estado sólido direto para o estado gasoso e vice-versa. Na água do mar, também temos íons formados pelo elemento iodo, como o iodato.

Então, a palavra líquido, presente na narrativa, será melhor pensada como sendo os sólidos iônicos, ou seja, os sais, dissolvidos na água formando um meio aquoso riquíssimo em íons, ou seja, uma solução aquosa iônica. O solvente água é o líquido de fato.

Podemos pensar na água do mar sob o aspecto de que ela pode funcionar como cicatrizante e proteger a nossa pele de inflamações e de bactérias perigosas, sendo antisséptico. Os benefícios do mar também podem ser pensados em relação ao movimento das ondas e às brisas marítimas que nos causam relaxamento e prazer. Nesse sentido podemos concordar com a narrativa quando se refere aos goles de água do mar como sendo "bons para a saúde de um corpo".

Entretanto, Lóri sabe que "fez um perigo" (LISPECTOR,1998, p.81); um desses perigos é o fato de a água do mar não ser boa para a saúde de um corpo em todos os 
aspectos, afinal de contas ela é "salgadíssima" (LISPECTOR,1998, p.79), mas a moça "bebe-a em goles grandes" (LISPECTOR,1998, p.80). Sabemos que ocorre a desidratação celular se bebermos a água do mar, devido ao fenômeno da osmose, importante tema trabalhado no ensino de Química.

É possível refletir sobre os desafios que nós, seres humanos, enfrentamos ao encararmos os desafios da vida, assim como Lóri enfrenta o desafio de viver o amor e a vida, apesar do medo daquilo que pode ser "traiçoeiro", como os perigos do mar. Dessa forma,natureza (ambiente) e humanidade podem ser discutidas a partir da leitura da narrativa da ida de Lóri ao mar.

\subsection{A crônica "Lixo"}

A crônica "Lixo" foi escrita por Luís Fernando Veríssimo e publicada pela primeira vez em 1981 (Araújo, 2014). É um diálogo entre dois vizinhos que conhecem aspectos da vida um do outro através da observação do lixo que cada um produz em suas casas.

Luis Fernando Veríssimo nasceu em 1936, é um autor gaúcho e entre outras coisas, roteirista e jornalista, tendo sido consagrado por diversas obras, muitas delas crônicas. De acordo com Simon (2011, p.19,20), a crônica é um texto literário com marcas de leveza, informalidade e irreverência, mas que também instiga o leitor. O papel dessa instigação no ensino é importante, pois temos na leitura da crônica uma oportunidade de motivar o aluno a questionar, discutir e refletir sobre determinadas questões.

Vale destacar aqui o seguinte trecho do diálogo:

- Só não fiquei com eles porque, afinal, estaria roubando. Se bem que, não sei: o lixo da pessoa ainda é propriedade dela?

-Acho que não. Lixo é domínio público.

-Você tem razão. Através do lixo, o particular se torna público. O que sobra de nossa vida privada se integra com a sobra dos outros. O lixo é comunitário. É a nossa parte mais social. Será isso? (VERÍSSIMO, 2013, p.90)

A partir do texto, é possível levantar questões sobre os tipos de lixo, as suas características, o seu aproveitamento pelo ser humano, o seu destino final, a sociedade de consumo que vivemos, a responsabilidade de cada um pelo lixo que gera e como o lidar com o lixo afeta a vida do ser humano. Constitui uma oportunidade de promoção de uma Educação Ambiental crítica no ensino escolar, de forma a desenvolver o exercício da cidadania e o senso crítico. Para Jacobi (2003) a educação ambiental tem um papel muito importante quando é exercida de forma crítica e transformadora, passando por espaços formais e não formais e focada no conhecimento do todo (homem, natureza e universo) de forma integrada.

Este texto serve como ponto de partida para a investigação dos diferentes materiais encontrados no lixo e a partir dessa investigação é possível trabalhar conteúdos químicos como as substâncias e transformações químicas relacionadas ao lixo.Santos eSchnetzler (1996) em uma pesquisa com educadores químicos, coloca que eles 
percebem a importância de os alunos adquirirem uma concepção de ciência como atividade em construção, sendo esta visão importante para que se dê ao ensino de Química o seu papel social.

Tendo em vista essas considerações, é possível pensar na abordagem do tema lixo no ensino de Química de forma a diminuir a lacuna existente entre a cultura cientifica e a cultura humanística no cotidiano escolar, onde geralmente o ensino é apresentado de forma compartimentalizada e quase sem diálogo com diferentes saberes. Acredita-se que a contextualização tem um papel importante na integração entre as duas culturas e de acordo com Franchi (2009) pode ser feita por meio de crônicas. Utilizando-se a temática promovida a partir do texto, é possível desenvolver uma Educação Ambiental crítica, ou seja, que fomenta o questionamento sobre a estrutura social e as condições de vida das pessoas a partir do uso e destino do lixo, sendo esta rica de elementos integradores entre as duas culturas.

\subsection{O conto de ficção científica "Água de Nagasáqui”.}

O conto de ficção científica “Água de Nagasáqui”foi escrito por Domingos Carvalho da Silva em 1965 (CAUSO, 2007). De acordo com Soares (2007) o conto é uma narrativa menor que um romance e representa apenas uma amostra representativa e singular da vida das personagens. Dessa forma, o conto é um recorte da vida dos personagense vai direto ao ponto que o autor quer mostrar.

Este conto apresenta a narração de um sobrevivente, de uma cidade próxima a Nagasáqui, do lançamento de bomba atômica na Segunda Guerra Mundial que bebe a água de um riacho da região e desde então passa a ser a causa da morte de várias pessoas por ter bebido a água "nagasaquiada". Assim, o personagem descreve:

Meteram-me numa ambulância, talvez para que, confinado em alguma cela de cimento, eu acabasse os meus dias. (...) Num dos meus camarotes de classe geral eu repousava com este esqueleto radioativo que continuava a luzir dentro de mim. (SILVA, 2007, p. 71)

O texto permite o aparecimento de questões como as causas e consequências do uso das bombas atômicas, a contaminação radioativa e a recuperação dos locais atingidos, a forma como ocorre essa contaminação, a distinção entre os fenômenos descritos no texto que de fato são reais daqueles que só ocorrem em uma história de ficção científica.

Oliveira e Santos (2017), em prática de ensino utilizando este conto em aula de Química com alunos do Ensino Médio, percebe que:

O trabalho do professor com as concepções dos alunos sobre a radioatividade a partir da leitura do conto possibilita que ideias partidas do senso comum, como por exemplo, a crença de que um objeto se torna radioativo ao receber radiação, possam ser reformuladas, abrindo espaço para a construção da chamada cultura elaborada .(OLIVEIRA e SANTOS,2017, p.69) 
Piassi (2015) aponta razões para o uso da ficção científica no ensino de Química, entre as quais temos: trabalhar questões científicas de interesse, realizar conexões entre ciência e sociedade, trabalhar o conhecimento de forma a superar concepções prévias dos estudantes que não estão de acordo com fatos científicosd. Piassi e Pietrocola (2009) colocam também que a literatura de ficção científica alia razão e emoção ao despertar sentimentos no leitor que o envolvem na história e o conduzem ao raciocínio e à reflexão sobre a realidade sociocultural.

A partir das ideias dos estudantes sobre o tema afloradas pela leitura e discussão do texto, a prática de ensino mencionada desenvolveu o tema radioatividade com o contexto histórico e social fornecido pelo texto. O envolvimento dos estudantes com a história narrada no conto, os links entre conteúdos químicos com histórico-sociais e o desenvolvimento das ideias levantadas pelos estudantes a partir da leitura do texto são fatos que evidenciam o rico potencial pedagógico do conto em questão ao ser utilizado em sala de aula.

\section{Considerações finais}

Este trabalho pontuou possibilidades de se trabalhar, a partir de textos literários, conhecimentos e reflexões relevantes tanto dentro de conhecimentos científicos da natureza quanto aspectos humanos,que não fazem parte de apenas uma área de conhecimento, mas que precisam da colaboração e da integração de diferentes saberes. Foi possível observar que os textos literários apresentam uma abordagem holística dos temas que apresentam, sem separá-los em disciplinas, envolvendo os estudantes leitores pela linguagem literária, mobilizando razão e emoção e dessa forma eles podem facilitar o desenvolvimento de conhecimentos e reflexões desejados em propostas pedagógicas a serem trabalhadas em sala de aula.

Dessa forma, espera-se que o trabalho em aulas de Química com os textos literários aqui apresentados contribua para uma formação humanística do estudante e para que essas aulas sejam interessantes e façam sentido para o aluno,ao mesmo tempo em que os conteúdos químicos são ensinados.

\section{Referências}

ARAÚJO, L. A. M. As marcas de oralidade na crônica de Luís Fernando Veríssimo. Verbum: Caderno de pós-graduação. São Paulo, n. 6, p.69-82,2014. $<$ https://revistas.pucsp.br/index.php/verbum/article/viewFile/19074/14485> Acesso em: 21 set. 2017.

CASTRO, M. A. de. Leitura: questões. Rio de Janeiro: Tempo Brasileiro,2015.

CAUSO, R. de S. (ed.). Os melhores contos brasileiros de ficção científica. São Paulo: Devir,2007. 
FRANCHI, S. J. S. A contextualização do ensino de Química por meio de crônicas. Dissertação de Mestrado.2009. 228p.Universidade Estadual de Campinas. Instituto de Química. Campinas.

GURGEL, I. WATANABE, G. A elaboração de narrativas em aulas de Física. A aprendizagem em Ciências como Manifestação Cultural. São Paulo: livraria da Física, 2017.

JACOBI, P. Educação Ambiental, cidadania e sustentabilidade.Cadernos de Pesquisa. Maranhão (UFMA), n.118, p 189-205, 2003.

LISPECTOR, C. Uma aprendizagem ou o livro dos prazeres. Rio de Janeiro: Rocco, 1998.

MORIN, E. A cabeça bem-feita. Repensar a reforma.Reformar o pensamento. 11 ed. Rio de Janeiro: Bertrand Brasil,2005.

MORA, A. M. S. A divulgação da ciência como literatura. Rio de Janeiro: Casa da Ciência: Editora UFRJ,2003.

OLIVEIRA, P. W, SANTOS, N. Paraense dos. Considerações sobre o uso de um conto de ficção científica no ensino de Química: radioatividade. In: MIRANDA, J. L. de, et.al. (org.). Ensino de Química em revista: o papel social do Ensino de Química. Rio de Janeiro: UFRJ, Instituto de Química, 2017. Disponível em: https://issuu.com/waldmir.neto/docs/livro pequi 2017. Acesso em 19 abril 2020.

PIASSI, L. P. de C. A ficção científica como elemento de problematização na educação em ciências. Ciência e Educação. Bauru, v.21, n.3, p.783-798,2015. Disponível em: http:/www.scielo.br/pdf/ciedu/v21n3/1516-7313-ciedu-21-03-0783.pdf. Acesso em: 19abril 2020.

PIASSI, L. P. de C.; PIETROCOLA, M. F. científica e ensino de ciências: para além do método de encontrar erros em filmes. Educação e Pesquisa. São Paulo, v.35, n.3, p.525-540,2009.

SANTOS, W. L. P. dos; SCHNETZLER, R. P.. Função social. O que significa ensino de Química para formar o cidadão?Química Nova na escola. n.4, novembro 1996.

SIMON, L. C. Duas ou três páginas despretensiosas: a crônica, Rubem Braga e outros cronistas. Londrina: EDUEL, 2011.

SILVA, D. C. Á. d. N.. In: CAUSO, Roberto de Sousa (ed.). Os melhores contos brasileiros de ficção científica. São Paulo: Devir,2007.

SILVEIRA, M. P. da. Literatura e Ciência: Monteiro Lobato e o ensino de Química.2013.297 f. Tese (Doutorado em Ciências) - Interunidades em Ensino de Ciências, Universidade de São Paulo, São Paulo. 
SOARES, A. Gêneros literários. 7 ed. São Paulo, Ática, 2007 (Série Princípios).

VERÍSSIMO, L. F. Lixo. In:

O melhor das comédias da vida privada. Rio de Janeiro: Objetiva, 2013. 